\title{
A Real-Car Experiment of a Dynamic Wireless Power Transfer System Based on Parallel-Series Resonant Topology
}

\author{
Toshiyuki Fujita ${ }^{1, * \mathbb{C}}$, Hiroyuki Kishi ${ }^{1}$, Hiroshi Uno ${ }^{2}$ and Yasuyoshi Kaneko ${ }^{2}$ \\ 1 Technova Inc., Tokyo 100-0011, Japan \\ 2 Course in Electrical and Electronic Systems/ School of Science and Engineering, Saitama University, \\ Saitama 338-8570, Japan \\ * Correspondence: t_fujita@technova.co.jp; Tel.: +81-3-3508-2280
}

Received: 15 April 2019; Accepted: 14 June 2019; Published: 20 July 2019

\begin{abstract}
A short mileage and long charging times are problems facing electric vehicles (EVs), and dynamic wireless power transfer (WPT) systems are one of the most effective solutions to overcome these shortcomings. This paper proposes a dynamic WPT system consisting of several stationary primary underground coils and a secondary coil on an EV. The dynamic WPT system employed solenoid coils that were superior to circular coils in terms of misalignment to the traveling direction. A dynamic WPT system rated at $25 \mathrm{~kW}$ was designed, constructed, and tested to verify the principles of operation; that is, the capability of supplying electric power continuously.
\end{abstract}

Keywords: solenoid coil; parallel series topology; distributed-coil arrangement; dynamic wireless power transfer

\section{Introduction}

An inductive wireless power transfer (WPT) system was considered for an electric vehicle (EV) or a plug-in hybrid vehicle (PHV) application. International standards for stationary (static) WPT systems are now being discussed by some international standards organizations [1-3]. The stationary system frees drivers from having to plug into EVs or PHVs, thus providing safety, convenience, and easiness to drivers. However, for this technology to be more broadly adopted, the vehicle-side coils installed on EVs are required to be smaller, lighter, more efficient in power transfer, more tolerant of lateral misalignments, and a large air gap. Stationary WPT systems have been developed for ten years [4-10].

However, even if stationary systems were introduced on the market, EVs would still have the following inevitable problems: A shorter mileage than internal-combustion-engine vehicles and a longer charging time than a fuel-filling time. In other words, stationary WPT systems will not decrease the charging time and will not increase the driving range. On the other hand, a dynamic WPT system is a solution to these problems, because the dynamic system is free from electric power charging similar to an electric train that feeds from power cables. Many types of dynamic WPT systems are proposed in a capacitive WPT system [11], an inductive WPT system including coil structure [12-14], connecting method and resonance topology [15,16], and feasibility [17]. Moreover, while comprehensive research on inductive dynamic WPT systems is currently in progress, as seen in [11] and [17-25], these do not show compelling experimental data. To discuss and compare results, an index or performance mark is urgently required.

This paper describes a dynamic WPT system. First, the configuration of the dynamic system is detailed. The system has multiple solenoid coils connected in parallel in input side. The topology is based on the parallel-series (PS). Second, a theoretical analysis of a stationary and dynamic system 
based on PS topology was compared with a measured one on the basis of an equivalent transformer. Third, the 25-kW dynamic WPT system was constructed and tested to verify fundamental characteristics in a bench test. Fourth, a 20-m dynamic WPT charging lane was arranged, and it demonstrated its principles of operation using a real car. Finally, some performance indexes were proposed to compare dynamic WPT systems based on the experiments presented in this paper.

\section{Experimental Setup}

\subsection{Circuit Configurations}

Figure 1 shows the circuit configuration of the dynamic WPT system considered in this paper, the topology of which is based on the PS connected WPT system. A voltage-controlled power-factor-correction (PFC) circuit or AC/DC converter was connected to the single-phase $200 \mathrm{~V}$, $50 \mathrm{~Hz}$ AC mains. The PFC configuration consists of a filter, a three-phase diode rectifier and a back converter. A full-bridge inverter was used for the ground-side coils. The filter was connected to the output of the inverter, which is designed for low-pass filter. The cutoff frequency of the filter is $100 \mathrm{kHz}$. The ground-side solenoid coils were connected in parallel with the primary resonant capacitors. Following this, the ground-side coils and resonant capacitors are referred to as ground-side coil sets. The vehicle-side solenoid coil was connected in series with the secondary resonant capacitor. A single-phase double current rectifier was used to achieve AC-to-DC power conversion at the receiving end [26].

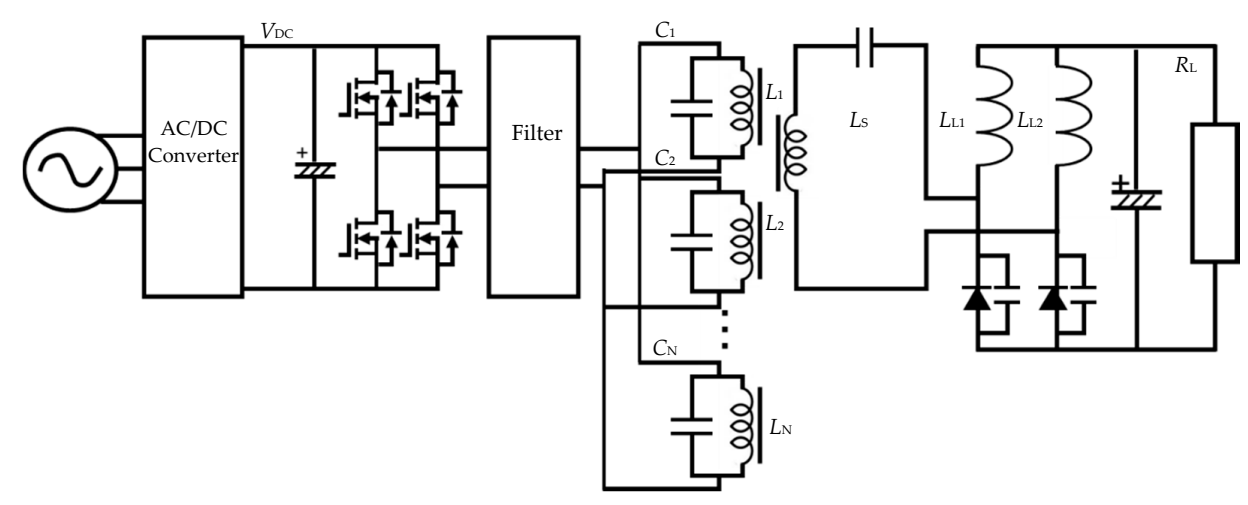

Figure 1. Construction of the experimental dynamic wireless power transfer (WPT) system.

This topology, as shown in Figure 1, has redundancy. Even if a ground side coil set is broken, the total dynamic WPT system can work without shutting down.

Table 1 summarizes the specifications of the dynamic WPT system in this experiment. The power capacity of these coils was rated at $25 \mathrm{~kW}$. The nominal air-gap length was $170 \mathrm{~mm}$. The inverter was operating at a high frequency of $85 \mathrm{kHz}$. H-shaped solenoid coils were chosen because of misalignment performance superiority to circular coils [27]. The inverter was made with $\mathrm{SiC}$ mosfets. The vehicle-side coil was installed with a water-cooling system to minimize its size and heatsink.

Table 1. Component specifications of the dynamic WPT system.

\begin{tabular}{|c|c|}
\hline System Components & Specifications \\
\hline Output power & $\operatorname{Max} 25 \mathrm{~kW}$ \\
\hline Air gap & $170 \mathrm{~mm}$ \\
\hline Frequency & $85 \mathrm{kHz}$ \\
\hline $\mathrm{AC} / \mathrm{DC}$ converter & Variable output voltage $^{1}$ \\
\hline Inverter & Full SiC FETs ${ }^{2}$ \\
\hline Rectifier & Double current rectifier \\
\hline Vehicle-side coil cooling & Water cooling \\
\hline
\end{tabular}




\subsection{WPT Coil Specifications}

Table 2 summarizes the specifications of the H-shaped solenoid coils used in this experiment. These coils were designed based on rated values of Table 1 and topology of Figure 1 . The ground-side coil dimensions were $620 \mathrm{~mm} \times 600 \mathrm{~mm} \times 40 \mathrm{~mm}$ and the vehicle-side coil were $430 \mathrm{~mm} \times 374 \mathrm{~mm} \times 38.5 \mathrm{~mm}$. The core of both the ground-side and vehicle-side coils were made of ferrite. The windings were laced with 1200 bundles of 0.1- $\phi$ litz wires.

Table 2. Specifications of the WPT coils.

\begin{tabular}{ccc}
\hline Side of Coil & Size $(\mathbf{m m})$ & Winding \\
\hline Ground-side & $620 \times 600 \times 40$ & $6 \mathrm{~T} \times 10 \mathrm{p}^{1}$ \\
Vehicle-side & $430 \times 374 \times 38.5$ & $45 \mathrm{~T} \times 1 \mathrm{p}$ \\
\hline & 1 "p" stands for parallel connection.
\end{tabular}

Figure 2 shows photographs of the WPT coils fabricated for this paper. The specifications are shown in Table 2.

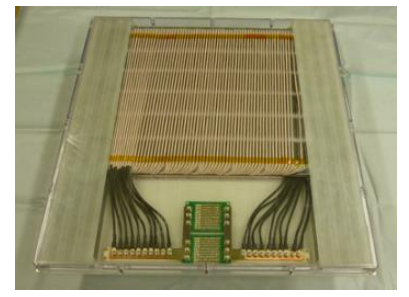

(a)

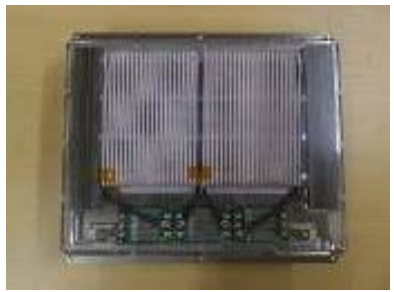

(b)

Figure 2. Photographs of the WPT coils tested in this paper. (a) Ground-side coil, (b) vehicle-side coil.

\subsection{WPT Coil Parameters}

Table 3 shows the experimental transformer parameters of the stationary WPT coils against aligned condition when the measured frequency was $85 \mathrm{kHz}$. The self-inductance of the ground-side coil $L_{N}$ and vehicle-side coil $L_{S}$ were 23.5 and $655 \mu \mathrm{H}$, respectively, while the subscript " $N$ " stands for the number of ground-side coils as shown in Figure 1. Winding resistances $r_{N}$ and $r_{\mathrm{S}}$ take into account skin and proximity effects and equivalent resistance for a ferrite core loss. The coupling coefficient $k$ between the ground-side coil and the vehicle-side coil at a 170-mm air-gap is 0.235.

Table 3. Experimental parameters of 25-kW WPT system at aligned condition.

\begin{tabular}{ccccc}
\hline$L_{N}$ & $L_{S}$ & $r_{N}$ & $r_{S}$ & $k$ \\
\hline $22.4 \mu \mathrm{H}$ & $658 \mu \mathrm{H}$ & $51.6 \mathrm{~m} \Omega$ & $1360 \mathrm{~m} \Omega$ & 0.235 \\
\hline
\end{tabular}

Figure 3 shows the experimental transformer parameters of the ground-side and vehicle-side coils against misalignment with the traveling direction of the vehicle ( $x$ direction), where $N=1$. Variation of $L_{N}$ and $L_{S}$ in this experiment were $3.1 \%$ and $4.8 \%$, respectively. Similarly, $r_{N}$ and $r_{\mathrm{S}}$ were $8.4 \%$ and $2.9 \%$. Mutual inductance between $L_{N}$ and $L_{S}$ at $x=300 \mathrm{~mm}$ decreases to half of the original value $(x=0 \mathrm{~mm})$. Consequently, the mutual inductance is almost zero at $x=900 \mathrm{~mm}$. 


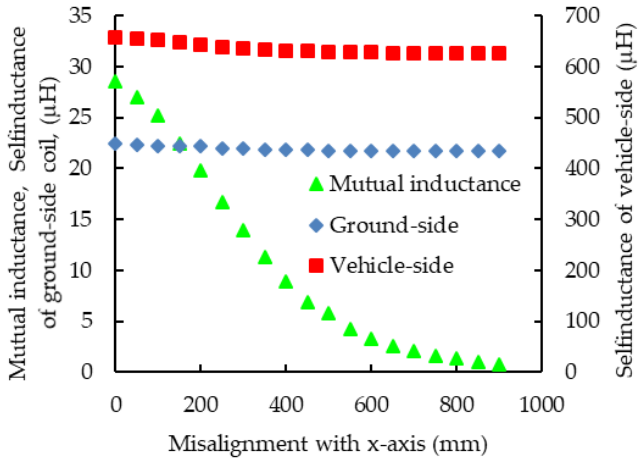

(a)

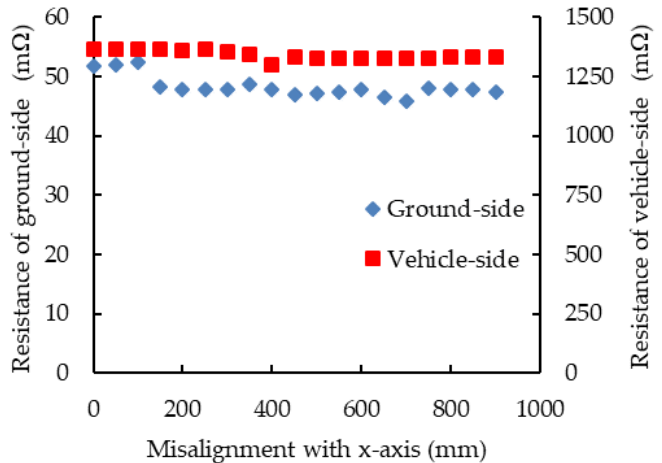

(b)

Figure 3. Experimental parameters of the WPT coils in case of the occurrence of misalignment. (a) Measured self and mutual inductances. (b) Measured equivalent resistances.

\section{Results}

\subsection{Transformer Analysis}

In this subsection, equivalent circuits for two WPT systems were analyzed. One stationary and one dynamic. Both were based on PS topology, and calculated with an impedance matrix. Since the winding resistances and the equivalent ferrite-core-loss resistance are lower than the mutual and self-resistances at the fundamental frequency, these resistances were neglected from the following subsection.

\subsubsection{Stationary System Analysis}

Figure 4 shows an equivalent circuit of the proposed stationary WPT system at a fundamental frequency. The input voltage and angular frequency are represented as $V_{\text {IN }}$ and $\omega$, assuming a sinusoidal voltage. The self-inductances of the ground-side coil and the vehicle-side coil are defined as $L_{P}$ and $L_{S}$, respectively. The mutual inductance between the ground-side and vehicle-side coils is defined as $M_{\text {PS }}$. The current and voltage directions are defined as shown in Figure 4.

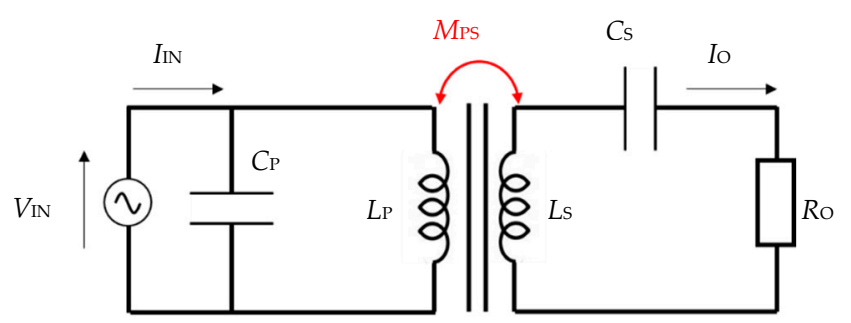

Figure 4. Equivalent circuit to the stationary WPT system.

Here, $V_{\mathrm{IN}}$ and $V_{\mathrm{O}}$ are given as

$$
\left(\begin{array}{c}
V_{\mathrm{IN}} \\
I_{\mathrm{IN}}
\end{array}\right)=\left(\begin{array}{cc}
\frac{L_{\mathrm{P}}}{M_{\mathrm{PS}}} & 0 \\
0 & \frac{M}{L_{1}}
\end{array}\right)\left(\begin{array}{c}
V_{\mathrm{O}} \\
I_{\mathrm{O}}
\end{array}\right)=\left(\begin{array}{cc}
\frac{1}{k} \sqrt{\frac{L_{\mathrm{P}}}{L_{\mathrm{S}}}} & 0 \\
0 & k \sqrt{\frac{L_{\mathrm{P}}}{L_{\mathrm{S}}}}
\end{array}\right)\left(\begin{array}{c}
V_{\mathrm{O}} \\
I_{\mathrm{O}}
\end{array}\right) .
$$

To achieve effective power transfer, the input power factor approximates unity. The resonant capacitors defined $C_{\mathrm{P}}$ and $C_{\mathrm{S}}$ are determined as

$$
C_{\mathrm{P}}=\frac{1}{\omega^{2} L_{\mathrm{P}}}, C_{\mathrm{P}}=\frac{1}{\omega^{2}\left(1-k^{2}\right) L_{\mathrm{S}}} .
$$

From Equation (1), the output voltage $V_{\mathrm{O}}$ increases linearly with the input voltage $V_{\text {IN }}$. This is similar to ideal transformer behavior but different in coefficient. The output voltage also increases the 
mutual inductances or coupling factor, as shown in Equation (1). If the input and output voltage is approximately equivalent, the self-inductance value of the secondary (vehicle-side) coil needs to be much higher than that of the primary (ground-side) coil.

The input impedance of Figure 4 is calculated by Equation (1) as

$$
\mathrm{Z}_{\mathrm{IN}}=\left(\frac{L_{\mathrm{P}}}{M_{\mathrm{PS}}}\right)^{2} R_{\mathrm{O}}=\frac{1}{k^{2}} \frac{L_{\mathrm{P}}}{L_{\mathrm{S}}} R_{\mathrm{O}}
$$

The input impedance is inversely proportional to the square of the coupling factor. When the vehicle-side coil is not above the ground-side coil, the input impedance of the WPT system increases to infinity. In other words, the proposed PS topology of the WPT system is stable and for the inverter not to over shoot at the input current, one does not need to install a high-response over current protection system at the inverter output line. Nevertheless, for safety reasons, an over current protection circuit was installed at the dc bus line to prevent unexpected situations.

\subsubsection{Dynamic System Analysis}

Figure 5 shows an equivalent circuit of the proposed dynamic WPT system at a fundamental frequency. For simplicity, the number of ground-side coils is limited to two. The definition is the same as in the previous subsection but different inductance values are used. The self-inductances of the first ground-side coil (coil 1), the second ground-side coil (coil 2) and the vehicle-side coil are defined as $L_{1}, L_{2}$ and $L_{S}$, respectively. The mutual inductances between coil 1 and coil 2, between coil 1 and the vehicle-side coil, and between coil 2 and the vehicle-side coil are defined as $M_{12}, M_{1 S}$ and $M_{2 S}$, respectively.

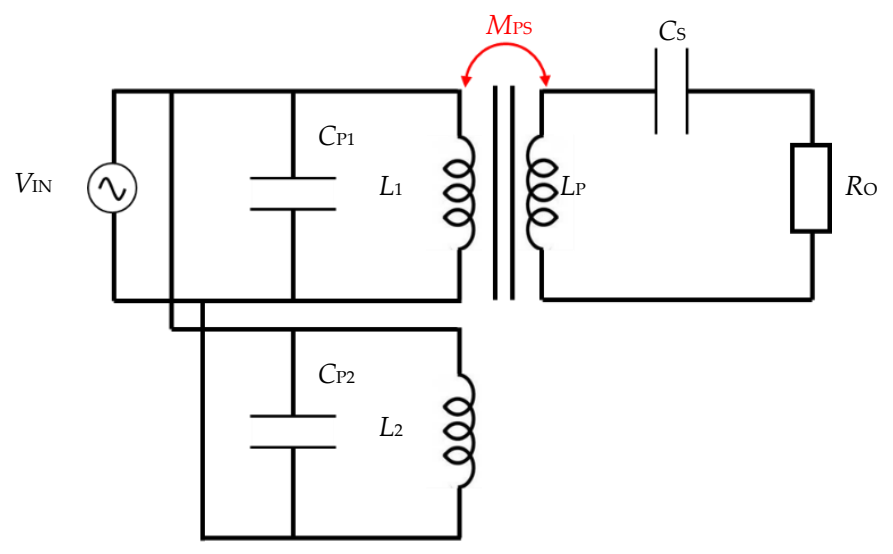

Figure 5. Equivalent circuit for the dynamic WPT system, with two ground-side coils.

Here, $V_{\mathrm{IN}}$ and $V_{\mathrm{O}}$ are given as

$$
\left(\begin{array}{c}
V_{\mathrm{IN}} \\
I_{\mathrm{IN}}
\end{array}\right)=\left(\begin{array}{cc}
\frac{1}{k_{1 S}+k_{2 S}} \sqrt{\frac{L}{L_{\mathrm{S}}}} & 0 \\
0 & \left(k_{1 \mathrm{~S}}+k_{2 \mathrm{~S}}\right) \sqrt{\frac{L_{\mathrm{S}}}{L}}
\end{array}\right)\left(\begin{array}{c}
V_{\mathrm{O}} \\
I_{\mathrm{O}}
\end{array}\right) .
$$

In this calculation, the self-inductances $L_{1}$ and $L_{2}$ have the same values as $L$, because the ground-side coils have identical shapes and windings. To achieve effective power transfer, the input power factor approximates unity. The resonant capacitors defined $C_{\mathrm{P} 1}, C_{\mathrm{P} 2}$ and $C_{\mathrm{S}}$ are determined as

$$
C_{\mathrm{P} 1}=C_{\mathrm{P} 2}=\frac{1}{\omega^{2} L}, C_{\mathrm{P}}=\frac{1}{\omega^{2}\left(1-k_{13}^{2}-k_{23}^{2}\right) L_{\mathrm{S}}} .
$$


From Equation (4), the output voltage $V_{\mathrm{O}}$ increases linearly with the input voltage $V_{\mathrm{IN}}$ in a similar fashion as for the stationary system but, with a difference of a coupling factor term. The term is the sum of the coupling factors which the vehicle-side coil interlinks with. In this case, the two ground-side coils. From this equation, the design concept of the vehicle-side coil is the same as the stationary WPT system, and the vehicle-side coil is able to use both the stationary and dynamic coils.

The input impedance of Figure 5 is calculated by Equation (4) as

$$
Z_{\mathrm{IN}}=\frac{1}{\left(k_{1 S}+k_{2 S}\right)^{2}} \frac{L}{L_{\mathrm{S}}} R_{\mathrm{O}}
$$

The input impedance is also the same as for the stationary system. As discussed above, the dynamic WPT system is stable enough for the inverter not to over shoot at the input current.

\subsection{Experimental Results}

\subsubsection{Stationary WPT System Results}

Figure 6 shows the experimental results with variation of input voltage $V_{\text {IN }}$. The circuit topology used was consistent with the topology detailed in Figure 1, and the number of ground-side coils, $N$, was one. Table 4 lists the experimental circuit parameters. The position of the vehicle-side coil was kept at a nominal air-gap of $170 \mathrm{~mm}$ without misalignment. The operating frequency in the inverter was set to $85 \mathrm{kHz}$ and was constant throughout the stationary experiment. The input voltage $V_{\mathrm{DC}}$ was proportional to the load voltage $V_{\mathrm{L}}$, as shown in Equation (4). Load power $P_{\mathrm{L}}$ was $25 \mathrm{~kW}$ and efficiency was measured as $85.5 \%$ at $V_{\mathrm{IN}}=485.6 \mathrm{~V}_{\mathrm{DC}}$ in Figure 1 . The theoretical output voltage $V_{\mathrm{L}}^{\prime}$ calculated by Equation (4) using Table 3 is $413.4 \mathrm{~V}$. However, the experimental output voltage $V_{\mathrm{L}}$ was 398.4 V. The difference between the theoretical and experimental voltage may be explained by the decision not to take into account the winding resistances within the WPT coils and the misalignment of resonant capacitors in theoretical value.

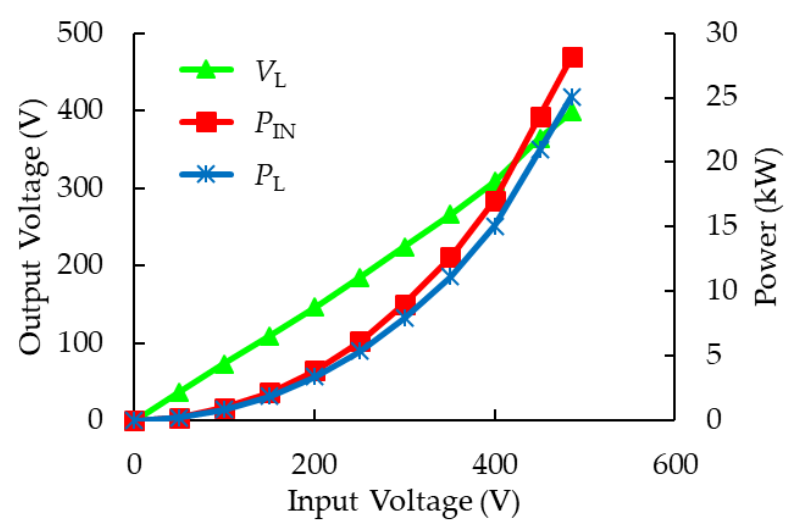

Figure 6. Experimental results of the stationary WPT system at the aligned condition as a function of input voltage $V_{\mathrm{DC}}$.

Table 4. Experimental parameters of 25-kW PWT system.

\begin{tabular}{ccccc}
\hline$C_{N}$ & $C_{S}$ & $L_{\mathrm{L} 1}$ & $L_{\mathrm{L} 2}$ & $\boldsymbol{R}_{\mathbf{L}}$ \\
\hline $17.3 \mathrm{nF}$ & $13.7 \mathrm{nF}$ & $300 \mu \mathrm{H}$ & $300 \mu \mathrm{H}$ & $7.6 \Omega$ \\
\hline
\end{tabular}

\subsubsection{Dynamic WPT System Test Bench Results}

Figure 7 shows the photograph of the dynamic WPT system used in the following bench test experiments. The bench test system consisted of five ground-side coils with the same topology described in Figure 1. The distance between each ground-side coil was $1200 \mathrm{~mm}$. The velocity of the 
vehicle-side coil was $28 \mathrm{~mm} / \mathrm{s}$. The input voltage $V_{D C}$ and frequency were controlled to be constant values of $240 \mathrm{~V}$ and $85 \mathrm{kHz}$, respectively. No other feedback loop was installed in this system.

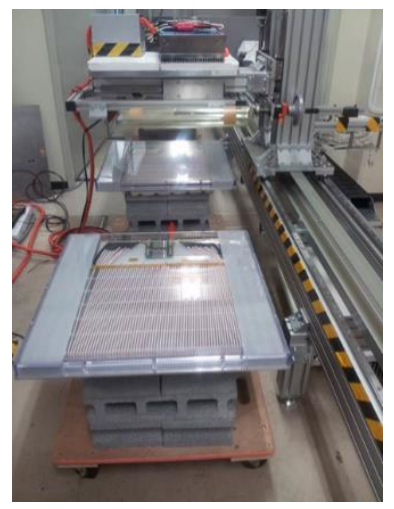

Figure 7. Photograph of the experimental dynamic WPT system in bench test.

Figure 8 shows the input and output power characteristics over time for the moving vehicle-side coil. The parameters are listed in Table 4. The peak values in Figure 8 occurred when the vehicle-side coil and the ground-side coils where aligned. This phenomenon resulted in PS characteristics and connecting a resistive load. The energy transmitted to the vehicle (receiving energy) from one ground-side coil to the next ground-side coil was around $65 \mathrm{Wh}$ under the conditions of this experiment. In addition, when the velocity of the vehicle-side coil was halved, the energy transmitted doubled. The power transfer from the experimental road to the vehicle was continuous for the duration of the test. The total energy conversion efficiency rate from the center of the first ground-side coil to that of the fifth one was $72.45 \%$.

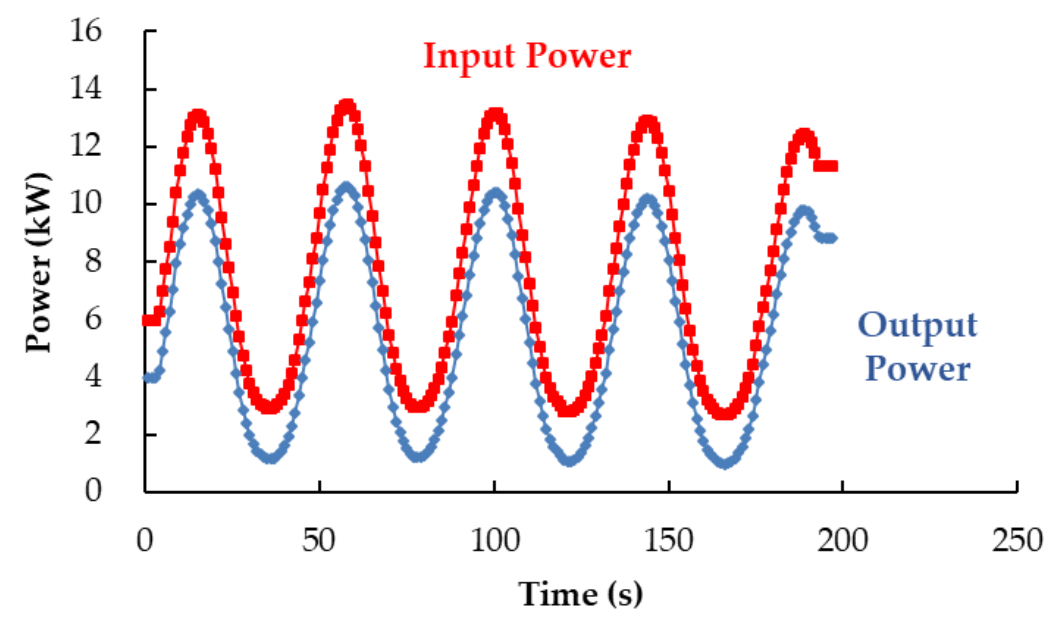

Figure 8. Experimental results of the dynamic WPT system in the bench test at $R_{\mathrm{L}}=7.6 \Omega$.

Figure 9 shows the input and output power characteristics over time for the moving vehicle-side coil. The parameters were the same as for Figure 8 and Table 4 except for the load condition. The load was a battery with a voltage $V_{\mathrm{L}}$ of $265 \mathrm{~V}$. As can be seen from Figure 9, there are times when the output power is equal to zero. This phenomenon results from PS characteristics and connecting a battery load. The transferred output voltage is also lower than the load voltage with a low coupling factor. The loss from the road power (i.e., ground-side coils), the filter and the inverter, was $1600 \mathrm{~W}$ in this system. The receiving energy of the vehicle from one ground-side coil to the next coil was around $28 \mathrm{Wh}$ for this experiment's conditions. The total energy conversion efficiency from the center of the first ground-side coil to the center of the fifth coil was $56.92 \%$. 


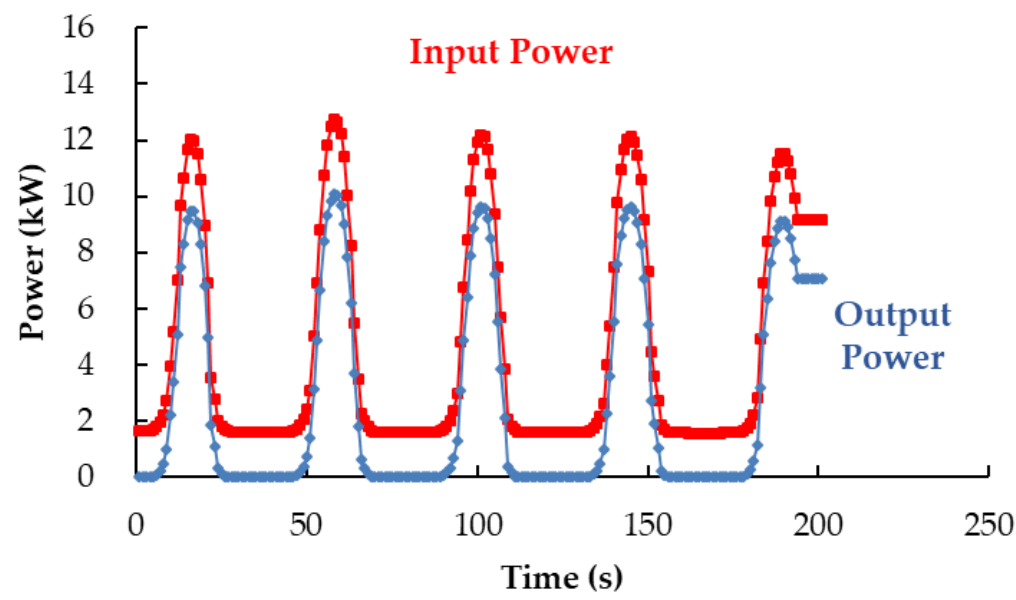

Figure 9. Experimental results of the dynamic WPT system in the bench test at $V_{\mathrm{L}}=265 \mathrm{~V}$.

\subsubsection{Dynamic WPT System Real-Car Test Results}

Figure 10 shows a photograph of the dynamic WPT system used in the following real-car test experiments. The circuit topology used was the same as in Figure 1 with $N=14$. The circuit parameters are listed in Table 5. The distance between each ground-side coil was $1200 \mathrm{~mm}$. The total length of the WPT system was $16.8 \mathrm{~m}$. The yellow and black lines placed on each side of the ground-side coils are guiding markers to help to driver to keep its trajectory straight. Al plates were also installed under the ground-side coils to reduce radiation. Note that the distance between the line from the filter to the ground-side coils was $23.5 \mathrm{~m}$ and the length of the air-gap between the WPT coils was measured at $170 \mathrm{~mm}$ when the vehicle-side coil was installed on the car. The output inverter voltage and current were controlled to not exceed 700 and 70 Arms for safety reasons.

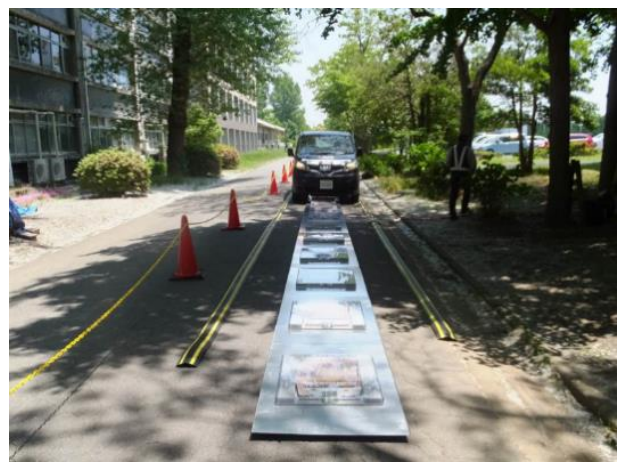

Figure 10. Photograph of the dynamic WPT system in the real-car test.

Table 5. Experimental circuit parameters of real-car test.

\begin{tabular}{ccccc}
\hline$C_{N}$ & $C_{\mathrm{S}}$ & $L_{1}$ & $L_{\mathbf{2}}$ & $V_{\mathrm{L}}$ \\
\hline $17.3 \mathrm{nF}$ & $13.7 \mathrm{nF}$ & $300 \mathrm{H}$ & $300 \mathrm{H}$ & $260 \mathrm{~V}$ \\
\hline
\end{tabular}

Figure 11 shows the output voltage and current characteristics over time for the running vehicle. The velocity of vehicle was $19 \mathrm{~km} / \mathrm{h}$. The peak current for each ground-side coil was not consistent. This resulted from the vehicle not being controlled to drive strictly straight, and the lines connecting each ground-side coil being longer than those used during the bench tests. Note that the applied voltage from the filter output point to the ground-side coils was dropped from 626 to 361 Vrms because of the length of the line was increased to $23.5 \mathrm{~m}$ between the filter and the coils. The total amount of energy received by the vehicle in this experiment was $2.14 \mathrm{Wh}$. 


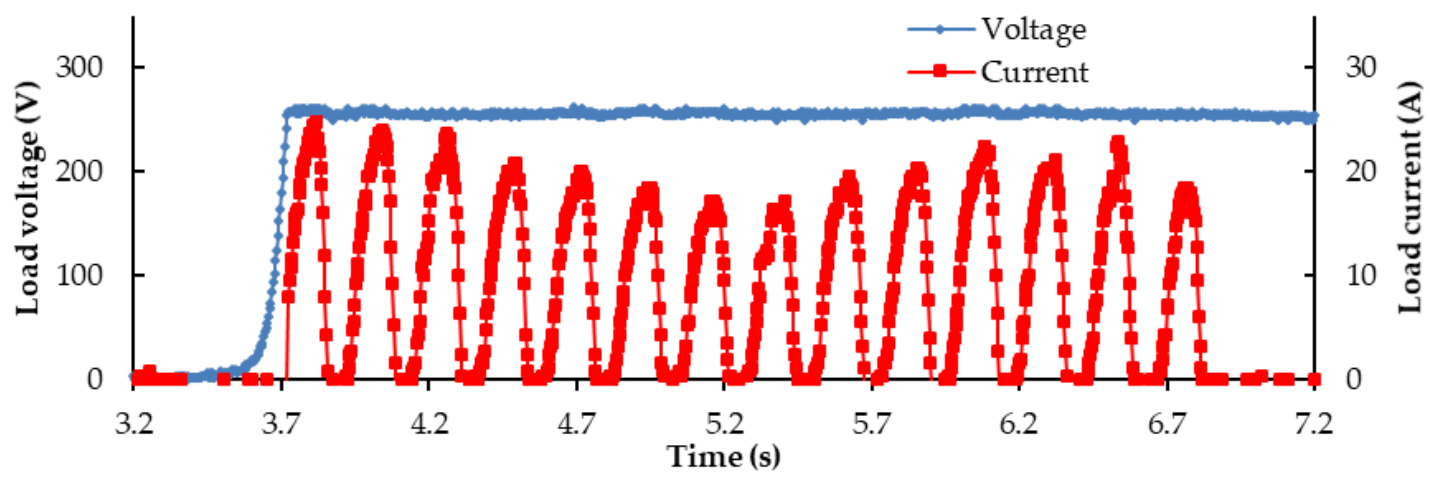

Figure 11. Experimental results of the load voltages and currents in the real-car test at vehicle velocity $v_{x}=19 \mathrm{~km} / \mathrm{h}$.

Figure 12 shows the output voltage and current characteristics over time for the running vehicle. The velocity of the vehicle was $52 \mathrm{~km} / \mathrm{h}$. The waveform of load current was the same as with the $19-\mathrm{km} / \mathrm{h}$ experiment except for the last 4 peaks and the time scale (i.e. division of $x$-axis on Figure 11 is $0.5 \mathrm{~s}$ and $0.2 \mathrm{~s}$ on Figure 12). This was due to the control delay in the inverter. The total energy received in that experiment was $0.5 \mathrm{Wh}$.

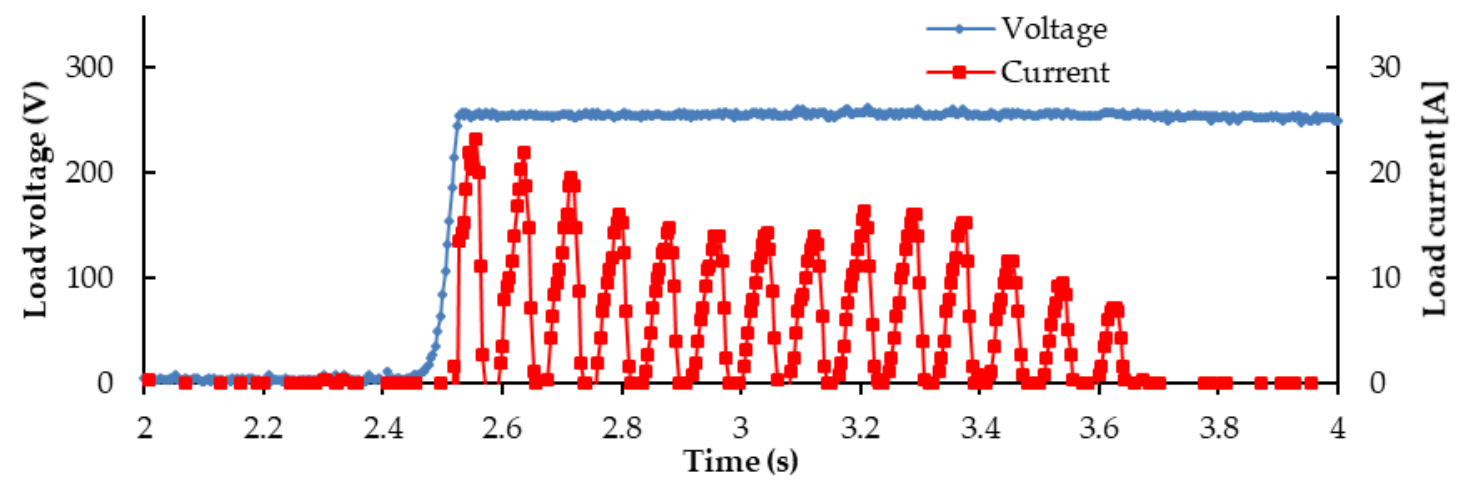

Figure 12. Experimental results of the load voltages and currents in the real-car test at vehicle velocity $v_{x}=52 \mathrm{~km} / \mathrm{h}$.

\section{Discussion}

Based on our experiments, we have come to the conclusion that in order to improve the effectiveness of the dynamic WPT system analyzed in this paper, one needs to solve the following problems. (a) Compensate the line impedance from source to the ground-side coils. The applied voltage at the ground-side coil is almost half of the output voltage at the filter. To solve this, the inverter should be put near the coils or compensated across capacitors. (b) Reduce the road-side loss. If more ground-side coils were added to the system, the loss increased. To reduce this, a switching method might be developed. (c) Compare the PS system and series-series (SS) system. This paper focused on a parallel-series based dynamic WPT system. However, we also tested a series-series based dynamic WPT system in previous research [15]. One should compare these two systems. (d) Increase receiving power between ground-side coils. The system examined in this paper had power drops between coils. A control method should be developed to increase the receiving power; i.e., an AC/DC converter with a feedback loop for power constant.

Table 6 shows a table that summarizes the experimental results contained in this paper. Total received energy and total energy conversion efficiency indexes are proposed to compare dynamic WPT systems. However, efficiency is not a time-independent variable and is not sufficient to demonstrate the performance of a dynamic WPT system. Total energy conversion efficiencies for real-car tests were 
difficult to establish, because of inconsistent start time when measuring passing's of the vehicle over ground-side coils. We considered that the total received energy is a robust index, which depends on vehicle velocity and input power or energy.

Table 6. Summary of experimental results.

\begin{tabular}{ccccc}
\hline Test Result in this Paper & $\begin{array}{c}\text { Receiving Power } \\
\mathbf{( k W )}\end{array}$ & Efficiency & $\begin{array}{c}\text { Total Energy } \\
\text { Conversion Efficiency }\end{array}$ & $\begin{array}{c}\text { Total Received } \\
\text { Energy (Wh) }\end{array}$ \\
\hline Stationary WPT system & 25 & $85.5 \%$ & - & - \\
Bench test for Resistance & 10.6 & $79.1 \%$ & $72.45 \%$ & 301 \\
Bench test for Battery & 10.1 & $79.2 \%$ & $56.92 \%$ & 149 \\
Real-car test $\left(v_{x}=19 \mathrm{~km} / \mathrm{h}\right)$ & 6.5 & $\mathrm{NA}$ & $\mathrm{NA}$ & 2.14 \\
Real-car test $\left(v_{x}=52 \mathrm{~km} / \mathrm{h}\right)$ & 5.9 & $\mathrm{NA}$ & $\mathrm{NA}$ & 0.5 \\
\hline
\end{tabular}

\section{Conclusions}

This paper has examined a 25-kW, PS topology based dynamic WPT system, based on a stationary WPT system and proposed reference indexes for a dynamic WPT system. First of all, the theoretical analysis developed in this paper concluded that the considered system could use an equivalent circuit to the one used for stationary WPTs. After that, the WPT system was empirically tested to validate the theoretical analysis under several conditions. Finally, to compare the performance of dynamic WPT systems under various conditions, we have advanced two variables: The total energy conversion efficiency and total receiving energy.

Author Contributions: Conceptualization, T.F., H.K. and Y.K.; data curation, T.F. and H.K.; formal analysis, H.U.; funding acquisition, H.K. and Y.K.; investigation, T.F. and H.U.; project administration, H.K. and Y.K.; resources, H.K.; supervision, Y.K.; validation, T.F.; visualization, T.F. and H.U.; writing-original draft, T.F.; writing一review and editing, H.K., H.U. and Y.K.

Funding: This research was funded by New Energy and Industrial Technology Development Organization, grant number 1208007.

Conflicts of Interest: The authors declare no conflict of interest. The sponsors had no role in the design, execution, interpretation, or writing of the study. The co-authors T.F. and H.K. are employee of Technova Inc. The company had a role in the decision to publish the results. And the co-authors T.F. and H.K did all the work of this paper during working time of Technova.

\section{References}

1. International Organization for Standardization. Electrically Propelled Road Vehicles-Magnetic Field Wireless Power Transfer-Safety and Interoperability Requirements; ISO/PAS 19363:2017; International Organization for Standardization: Geneva, Switzerland, 2017.

2. International Electrotechnical Commission. Electric Vehicle Wireless Power Transfer (WPT) Systems-Part 1: General Requirements; IEC 61980-1:2015; International Electrotechnical Commission: Geneva, Switzerland, 2015.

3. Society of Automotive Engineers recommended practice J2954. Wireless Power Transfer for Light-Duty Plug-In/Electric Vehicles and Alignment Methodology J2954_201904; Society of Automotive Engineers Recommended Practice: Warrendale, PA, USA, 2019.

4. Low, Z.N.; Chinga, R.A.; Tseng, R.; Lin, J. Design and test of a high-power high-efficiency loosely coupled planar wireless power transfer system. IEEE Trans. Ind. Electron. 2008, 56, 1801-1812.

5. Shimizu, R.; Kaneko, Y.; Abe, S. A new he core transmitter of a contactless power transfer system that is compatible with circular core receivers and H-shaped core receivers. In Proceedings of the 2013 3rd International Electric Drives Production Conference (EDPC), Nuremberg, Germany, 29-30 October 2013; pp. 369-375.

6. Diekhans, T.; Doncker, R.W. A dual-side controlled inductive power transfer system optimized for large coupling factor variations and partial load. IEEE Trans. Power Electron. 2015, 30, 6320-6328. [CrossRef] 
7. Takanashi, H.; Sato, Y.; Kaneko, Y.; Abe, S.; Yasuda, T. A large air gap $3 \mathrm{~kW}$ wireless power transfer system for electric vehicles. In Proceedings of the 2012 IEEE Energy Conversion Congress and Exposition (ECCE), Raleigh, NC, USA, 15-20 September 2012; pp. 269-274.

8. Imura, T.; Okabe, H.; Hori, Y. Basic experimental study on helical antennas of wireless power transfer for Electric Vehicles by using magnetic resonant couplings. In Proceedings of the 2009 IEEE Vehicle Power and Propulsion Conference, Dearborn, MI, USA, 7-11 September 2009; pp. 936-940.

9. Nagatsuka, Y.; Ehara, N.; Kaneko, Y.; Abe, S.; Yasuda, T. Compact contactless power transfer system for electric vehicle. In Proceedings of the IEEE 2010 International Power Electronics Conference-ECCE, Sapporo, Japan, 21-24 June 2010; pp. 807-813.

10. Ombach, G.; Kurschner, D.; Mathar, S.; Chlebosz, W. Optimum magnetic solution for interoperable system for stationary wireless EV charging. In Proceedings of the 2015 Tenth International Conference on Ecological Vehicles and Renewable Energies (EVER), Monte Carlo, Monaco, 31 March-2 April 2015; pp. 1-8.

11. Hanazawa, M.; Ohira, T. Power transfer for a running automobile. In Proceedings of the 2011 IEEE MTT-S International Microwave Workshop Series on Innovative Wireless Power Transmission: Technologies, Systems, and Applicationsin, Kyoto, Japan, 12-13 May 2011; pp. 77-80.

12. Covic, G.A.; Boys, J.T. Modern trends in inductive power transfer for transportation applications. IEEE J. Emerg. Sel. Top. Power Electron. 2013, 1, 28-41. [CrossRef]

13. Kim, J.; Kim, J.; Kong, S.; Kim, H.; Suh, I.-S.; Suh, N.P.; Cho, D.-H.; Kim, J.; Ahn, S. Coil design and shielding methods for a magnetic resonant wireless power transfer system. Proc. IEEE 2013, 101, 1332-1342. [CrossRef]

14. Lu, F.; Zhang, H.; Hofmann, H.; Mi, C.C. A dynamic charging system with reduced output power pulsation for electric vehicles. IEEE Trans. Ind. Electron. 2016, 63, 6580-6590. [CrossRef]

15. Fujita, T.; Yasuda, T.; Akagi, H. A dynamic wireless power transfer system applicable to a stationary system. IEEE Trans. Ind. Appl. 2017, 53, 3748-3757. [CrossRef]

16. Jeong, S.; Jang, Y.J.; Kum, D. Economic analysis of the dynamic charging electric vehicle. IEEE Trans. Power Electron. 2015, 30, 6368-6377. [CrossRef]

17. Wang, C.S.; Covic, G.A.; Stielau, O.H. Power transfer capability and bifurcation phenomena of loosely coupled inductive power transfer systems. IEEE Trans. Ind. Electron. 2004, 51, 148-157. [CrossRef]

18. Sato, F.; Murakami, J.; Suzuki, T.; Matsuki, H.; Kikuchi, S.; Harakawa, K.; Osada, H.; Seki, K. Contactless energy transmission to mobile loads by CLPS-test driving of an EV with starter batteries. IEEE Trans. Magn. 1997, 33, 4203-4205. [CrossRef]

19. Showa Aircraft Industry Co. Ltd.; Tohoku University; Nissan Motor Co. Ltd. RED Program for Innovative Energy Efficiency Technology, Exploratory Research Phase, a Development of Inductive Power Supply System for Moving Vehicles (FY2010-FY2012) FY2012 Final Report; Japan no. 20140000000045; NEDO: Kawasaki, Japan, 2014.

20. Huh, J.; Lee, S.W.; Lee, W.Y.; Cho, G.H.; Rim, C.T. Narrow-width inductive power transfer system for online electrical vehicles. IEEE Trans. Power Electron. 2011, 26, 3666-3679. [CrossRef]

21. Covic, G.A.; Boys, J.T.; Kissin, M.L.G.; Lu, H.G. A three-phase inductive power transfer system for roadway-powered vehicles. IEEE Trans. Ind. Electron. 2007, 54, 3370-3378. [CrossRef]

22. Ean, K.K.; Imura, T.; Hori, Y. New Wireless Power Transfer via Magnetic Resonant Coupling for Charging Moving Electric Vehicle. In Proceedings of the EVTeC and APE Japan 2014, Yokohama, Japan, 22-24 May 2014; pp. 1-5.

23. Kim, J.W.; Son, H.-C.; Kim, D.; Yang, J.; Kim, K.; Lee, K.; Park, Y. Wireless power transfer for free positioning using compact planar multiple self-resonators. In Proceedings of the 2012 IEEE MTT-S International Microwave Workshop Series on Innovative Wireless Power Transmission: Technologies, Systems, and Applications, Kyoto, Japan, 10-11 May 2012; pp. 127-130.

24. Prasanth, V.; Bauer, P. Distributed IPT systems for dynamic powering: Misalignment analysis. IEEE Trans. Ind. Electron. 2014, 61, 6013-6021. [CrossRef]

25. Fujita, T.; Kishi, H. A study of a dynamic wireless power transfer system based on parallel- series resonant topology-Bench test and real car test. In Proceedings of the EVS31 and EVTeC2018, Kobe, Japan, 30 September-3 October 2018. 
26. Fujita, T.; Yasuda, T.; Akagi, H. A wireless power transfer system with a double-current rectifier for EVs. In Proceedings of the 2016 IEEE Energy Conversion Congress and Exposition (ECCE), Milwaukee, WI, USA, 18-22 September 2016; pp. 1-7.

27. Chigira, M.; Nagatsuka, Y.; Kaneko, Y.; Abe, S.; Yasuda, T.; Suzuki, A. Small-size light-weight transformer with new core structure for contactless electric vehicle power transfer system. In Proceedings of the 2011 IEEE Energy Conversion Congress and Exposition, Phoenix, AZ, USA, 17-22 September 2011; pp. 260-266.

(C) 2019 by the authors. Licensee MDPI, Basel, Switzerland. This article is an open access article distributed under the terms and conditions of the Creative Commons Attribution (CC BY) license (http://creativecommons.org/licenses/by/4.0/). 